\title{
Strategic Trade: Weighted Payoff Functions And Diverse Trade Patterns
}

\author{
Gregory G. Green, (Email: greegreg@isu.edu), Idaho State University
}

\begin{abstract}
This paper extends the basic intra-industry trade model, Brander and Spencer (1985), in two directions. A weight is included in the foreign government's payoff function, similar to Collie (1997), which alters the traditional policy choice when this weight is different than one. We also require each firm's output choice be nonnegative. These constraints and the weighted payoff function lead to several Nash equilibria that have not been analyzed in the intra-industry trade literature. Our analysis helps explain why industries satisfying the necessary conditions for intraindustry trade patterns may not actually display such trade patterns. [F12, F13, C72]
\end{abstract}

\section{Introduction}

B rander and Spencer (1985) identified a set of circumstances where free trade was not an equilibrium. This occurs in a trade setting where two firms compete as Cournot oligopolists in two separate markets. Their analysis provides a straightforward description of how to derive a Nash equilibrium trade policy in an imperfectly competitive model of trade. For those industries that fit the description of this model there is an inherent tendency for individual firm's to lobby for industrial policy, where we define industrial policy to be any trade policy that places more weight on one group's payoff than some other group's payoff within the social benefit function; for example, a policy that favors firms at the expense of consumers or the government would be an industrial policy. The Brander and Spencer (1985) subsidies provide a baseline for comparing industrial policy in an oligopoly setting. Their subsidies would not be considered industrial policy using the above definition, because each sector receives equal weight in the social benefit function.

Industrial policy will manifest itself through trade policy and the producing firms output choices. The objective of this research is to identify and analyze the mathematically obvious forms of industrial policy. The analysis deals exclusively with a trade structure that can be described within a Brander and Spencer framework. To analyze industrial policy a weight is placed inside the foreign governments social benefit function. As the weight varies we identify the Nash equilibrium trade policy, and the changing output choices of firms. The analysis leads to several interesting conclusions. One conclusion is that the measure of actual social benefit, as defined by Collie (1997), can increase if firms receive a weight less than one in the social benefit function. This result should help repel lobbying behavior from oligopolistic firms. A second conclusion is that a strictly interior solution, nonnegative output choices, will not exist for some values of the weight. For example, if the weight exceeds some plausible critical level the model predicts no trade at all. Firms will act as monopolists in their respective domestic economy.

While the first conclusion is interesting Collie (1997) has already identified this outcome in a reduced form of this papers model. This research extends Collie's model and leads directly to the second contribution of this paper. Some firms that satisfy the necessary conditions for intra-industry trade do not experience a pure form of such trade patterns. For example, Boeing and Airbus satisfy the necessary conditions for intra-industry trade; however, Boeing dominates commercial airframe sales in the United States, while in the rest of the world these firms behave more like Cournot oligopolists. The analysis suggests that these trade patterns are a result of a weight

Readers with comments or questions are encouraged to contact the author via email. 
greater than one being placed on the firm's profit function within the social benefit function, or a conscious choice of a Nash equilibrium trade policy that is not subgame perfect.

Trandel and Skeath (1996) have also analyzed the impacts of an unequal weighting in the social benefit function. Their modeling approach is slightly different than the present work. In their model all trade takes place in some common third market. While this modeling structure provides many insights into industrial policy, and was the impetuous for the present work, it seems more natural to extend Collie's (1997) model instead. In the more general setting many of Trandel and Skeath's results will be reversed. This is not to be viewed as a weakness in Trandel and Skeath's argument. Rather it is a consequence of consumption occurring in each of the producing countries, and a tariff being collected on imports.

The paper proceeds as follows. In section 2 we present the model. In section 3 we derive and summarize all of the Nash equilibria. In section 4 we analyze each Nash equilibrium and the trade pattern associated with the each equilibrium. In this section we also check if one of the equilibrium outcomes is preferred to the other equilibrium outcomes. In section 5 we offer conclusions.

\section{The Model}

The model that we construct is a natural extension of Collie's (1997). We extend his model by allowing both governments an export subsidy and import tariff. The model is a four-player two-stage game. In stage one the domestic and the foreign governments simultaneously choose trade policy. Given stage-one trade policy two firms, one a domestic firm the other a foreign firm, compete as Cournot oligopolists in the domestic and foreign markets.

Each government will choose an export subsidy, $s^{i} \in S_{i}$ and an import tariff, $t^{i} \in T_{i}$ for $i=d$ and $f$, where $d$ represents a policy of the domestic government and $f$ represents a policy of the foreign government. The choice of trade policy will alter the domestic and foreign firms market share. The policy will also cause a redistribution of income between consumers, the government, and the oligopolist. For notational convenience let $P=S_{1} \times T_{1} \times$ $S_{2} \times T_{2}$ represent all possible policy combinations, and let $t \in P$ represent an arbitrary choice of trade policy.

Any stage-one policy choice will impact the stage-two output choice of the foreign and domestic firms. The domestic firm will choose an output level $x^{d} \in X_{d}$, which it then sells in the domestic market, and $x^{f} \in X_{f}$, which it exports to the foreign market. Likewise, the foreign firm exports $y^{d} \in Y_{d}$ to the domestic market and produces $y^{f}$ $\in Y_{f}$ for the foreign (its domestic) market. Thus, $x^{d}+y^{d}$ and $x^{f}+y^{f}$ represent total domestic and foreign sales respectively. For notional convenience let $X=X_{d} \times X_{f} \times Y_{d} \times Y_{f}$ represent all possible output combinations and let $x$ $\in X$ represent an arbitrary choice of output for each firm and each market.

We assume that the inverse demand function is linear and identical across countries. Let $p\left(x^{d}+y^{d}\right)=a-$ $b\left(x^{d}+y^{d}\right)$ represent domestic demand for the output of these firms, and let $p\left(x^{f}+y^{f}\right)=a-b\left(x^{f}+y^{f}\right)$ represent foreign demand for the output of these firms. Furthermore, we assume that each firm has a constant cost per unit, $c$. The parameters $a, b$, and $c$, are all positive real numbers and to make economic sense we assume $a>c$.

All equilibria are in pure strategies and are found using subgame-perfection via backward induction. Thus, stage two is solved prior to stage one. For this reason we introduce the firms payoff functions prior to the governments. Let

$$
\pi^{d}(t, x)=\left(p\left(x^{d}+y^{d}\right)-c\right) x^{d}+\left(p\left(x^{f}+y^{f}\right)-c+s^{d}-t^{f}\right) x^{f}
$$

represent the profit function of the domestic firm and let

$$
\pi^{f}(t, x)=\left(p\left(x^{d}+y^{d}\right)-c+s^{f}-t^{d}\right) y^{d}+\left(p\left(x^{f}+y^{f}\right)-\mathrm{c}\right) y^{f}
$$

represent the profit function of the foreign firm. 
We suppose that firm's are profit maximizers in a Cournot sense. To solve the maximization problem, and find the Nash equilibria, we must derive each firm's first order conditions from the payoff functions defined above. This implicitly defines the reaction functions of these firms. Given the firms objective to maximize profits

$$
\begin{array}{ll}
\pi_{x d}^{d}=\left(-2 b x^{d}-b y^{d}+a-c\right) x^{d}=0 & x^{d} \geq 0, \\
\pi_{x f}^{d d}=\left(-2 b x^{f}-b y^{f}+a-c+s^{d}-t^{f}\right) x^{f}=0 & x^{f} \geq 0, \\
\pi_{y d}^{f}=\left(-b x^{d}-2 b y^{d}+a-c+s^{f}-t^{d}\right) y^{d}=0 & y^{d} \geq 0, \\
\pi_{y f}^{f}=\left(-b x^{f}-2 b y^{f}+a-c\right) y^{f}=0 & y^{f} \geq 0,
\end{array}
$$

define the implicit reaction functions, where $\pi_{j}^{i}$ is the partial derivative of firm $i$ 's payoff function with respect to variable $j$.

Non-negativity constraints introduce fifteen potential corner solutions and one interior solution. While sixteen potential solutions exist only five are Nash equilibria. Of these five Nash equilibria two are subgame perfect for some values of the weight, $\theta$, which is yet to be defined. We summarize the equilibrium outcomes in Table 1 and analyze each case in section 3 .

Table 1: Subgame Perfect Equilibria

\begin{tabular}{lllll}
\hline Cases & $x^{d}$ & $x^{f}$ & $y^{d}$ & $y^{f}$ \\
\hline case 1 & $>0$ & $>0$ & $>0$ & $>0$ \\
case 2 & $>0$ & $>0$ & $=0$ & $>0$ \\
case 3 & $>0$ & $=0$ & $>0$ & $>0$ \\
case 4 & $>0$ & $=0$ & $=0$ & $>0$ \\
case 5 & $=0$ & $=0$ & $>0$ & $>0$ \\
\hline
\end{tabular}

We suppose that the governments are maximizing some social benefit function. For each government social benefit is defined as the sum of the respective domestic consumer surplus, derived from the consumption of good $X$, the profit of the respective domestic oligopolist, and the government's collection of taxes less the distribution of subsidies. ${ }^{1}$ Following Dixit (1984) let

$$
g^{d}(t, x)=\left(b\left(x^{d}+y^{d}\right)^{2}\right) / 2+\pi^{d}(t, x)+t^{d} y^{d}-s^{d} x^{f}
$$

represent the domestic government's payoff function and let

$$
g^{f}(t, x)=\left(b\left(x^{f}+y^{f}\right)^{2}\right) / 2+\pi^{f}(t, x)+t^{f} x^{f}-s^{f} y^{d}
$$

represent the foreign government's payoff function. We assume that eqs (7) and (8) describe actual social benefits. However, the foreign government chooses trade policy as if maximizing

$$
g^{f^{*}}(t, x)=\left(b\left(x^{f}+y f\right)^{2}\right) / 2+\theta \pi^{f}(t, x)+t^{f} x^{f}-s^{f} y^{d}
$$

Thus, the foreign firm's profit receives a different weight in eq (9) than it does in eq (8). ${ }^{2}$ The value taken by $\theta$ will determine which Table 1 outcome, if any, is a preferred outcome, where we say that one equilibrium outcome $(t, x)$ is preferred to another outcome $(t, x) *$ if $g^{i}(t, x) \geq g^{i}(t, x)^{*}$ for both governments $i=d$ and $f$.

\footnotetext{
${ }^{1}$ For a justification of this specification see Dixit (1984).

${ }^{2}$ Because the payoff functions are symmetric placing a weight in the domestic government's payoff function on the domestic firms profits does not generate new information.
} 


\section{Analysis}

In this section, we derive and analyze the Nash equilibria identified in Table $1 .{ }^{3}$ Each equilibria, summarized in propositions $1-4$, defines a distinct trade pattern, an optimal policy, and the dependence of the equilibrium on $\theta$. We then analyze the welfare impacts for both countries involved in trade.

\subsection{Case 1: The Standard Outcome}

Case 1 assumes that all output levels are positive, which is the standard interior solution. This case is solved, as are all others, using subgame-perfection via backward induction. Thus, the procedure is straightforward. Set, eqs (3) - (6) equal to zero and simultaneously solve for output levels as a function of trade policy. These values are then substituted into eqs (7) and (9) making the government payoff functions a function of trade policy only. The domestic government's payoff function is then differentiated with respect to $s^{d}$ and $t^{d}$ and the foreign governments payoff function is differentiated with respect to $s^{f}$ and $t^{f}$. The simultaneous solution to these first order conditions will define the Nash equilibrium trade policy. Substitution of the Nash equilibrium trade policy into the recently derived simultaneous solution of eqs (3) - (6) will define the Nash equilibrium output choice for each firm. Following this procedure the case 1 Nash equilibrium is

$$
\begin{aligned}
& \left.\left(s^{d}, t^{d}\right)=((a-c)(2 \theta-3) /(2(2 \theta-9)),(a-c)(4 \theta-9)) /(2(8 \theta-15))\right), \\
& \left(s^{f}, t^{f}\right)=((4 \theta-3)(a-c) /(2(15-8 \theta)),(-3-2 \theta)(a-c) /(2(2 \theta-9))), \\
& \left(x^{d}, x^{f}\right)=((4 \theta-7)(a-c) /((8 \theta-15) b),(2 \theta-3)(a-c) /((2 \theta-9) b)), \\
& \left(y^{d}, y^{f}\right)=((a-c) /((15-8 \theta) b), 3(a-c) /((9-2 \theta) b)) .
\end{aligned}
$$

Analysis of eqs (10) - (13) will determine the values of $\theta$ that will guarantee non-negative output. What we find is that $0 \leq \theta<3 / 2$ guarantees that the non-negativity constraints will bind. ${ }^{4}$

The results of this subsection are summarized in

Proposition 1: The strategy $(t, x)^{N E}$ defined by eqs (10) - (13) is an interior, case 1, subgame-perfect equilibrium for all $\theta \in[0,3 / 2)$.

The Nash equilibrium strategy defined in Proposition 1 will generate payoffs for all players that are a positive constant times some polynomial in $\theta$. Since the constant is positive we can analyze the polynomials in $\theta$ to determine the behavior of payoffs as this weight changes.

The effect of $\theta$ on the domestic government is somewhat intuitive. For $0 \leq \theta<0.9044$ the domestic government's payoff will decline with changes in $\theta$. However, for $0.9044<\theta<3 / 2$ the domestic government's payoff will increase. This latter result is caused by a combination of effects. First, tariff collection will be increasing as $\theta$ increases; similarly subsidy payments will be declining as the domestic firm reduces its exports. Consumer surplus will also be increasing in $\theta$, the amount of $x$ available for domestic sale will be increasing. All of these increases will exceed the decrease in the domestic firm's profit. If the domestic firm were to lobby its government to counter its reduction in market share its government could respond with an increase in $t^{d}$, since the tariff is increasing in $\theta$. The government may also respond with a decrease in $s^{d}$ since the subsidy is decreasing in $\theta$. This outcome seems politically palatable since increasing $t^{d}$ appears to benefit the domestic industry while decreasing $s^{d}$ appeals to the rest of the world.

\footnotetext{
${ }^{3}$ Each is subgame perfect for select values of $\theta$.

${ }^{4}$ The boundary $3 / 2$ in our analysis is the same boundary discovered by Trandel and Skeath. However, their boundary defined the maximum value that their weight could take, while for us $3 / 2$ defines the upper bound on $\theta$ for an interior solution to exist.
} 
If eq (9) were the measure of foreign welfare then welfare would be increasing for all $0 \leq \theta<3 / 2$. However, since we've claimed that actual benefits are measured by eq (8) we find that foreign social benefit is increasing in $\theta$ for $0 \leq \theta<0.7167$, for $0.7167<\theta<3 / 2$ foreign social benefit is decreasing in $\theta$. Apparently if the foreign government were going to weight its domestic firm's profit with a weight other than one it would increase domestic benefit to use a weight less than one. If the foreign government could choose $\theta=0.7167$ then $t^{f}$ and $s^{f}$ would be smaller than the $\theta=1$ case. If we restrict $1 \leq \theta$ as in Trandel and Skeath (1996) the foreign government should never favor its exporting firm. With $\theta>1$ the foreign government should expect to increase the subsidy payment $s^{f}$ with any increase in $\theta$. Both $t^{d}$ and $t^{f}$ are increasing in $\theta$. Thus, as $\theta$ increases foreign consumers will notice an overall reduction in $X$. The consequence of this reduction in output will outweigh the increase in the foreign firm's profit. In essence this result reverses one of Trandel and Skeath's (1996) results, which states that a government can increase its social benefit by increasing the weight it assigns to its domestic firm's profit. The reversal occurs because we include a tariff policy and trade is occurring between the producing countries and not in some third country.

Similarly, this analysis reinforces one of Collie's (1997) outcomes. If the foreign government should choose $\theta \in[1,3 / 2)$ then the domestic government should allow the favoritism. The domestic firm may not prefer this outcome but domestic consumers will be better off.

We have implicitly discussed the impact on firms of a $\theta \neq 1$. However, to be explicit the domestic firm's profit will fall as $\theta$ rises, while the foreign firm's profit will rise with a rise in $\theta$.

Case 2, the domestic firm is a monopolist in the domestic economy, of Table 1 is an equilibrium for $0 \leq \theta<$ $3 / 2$ as in case 1 . However, analysis of case 2 leads us to the conclusion that the case 1 payoff is preferred to case 2 payoffs. Therefore, we do not present the analysis of case $2 .^{5}$

\subsection{Case 3: Foreign Firm Is A Monopolist In The Foreign Economy}

This case is very similar to case 2 except that $x^{f}=0$ while all other output levels are positive. Consequently the reaction function of eq (4) must be less than or equal to zero. Furthermore, with $x^{f}=0$ eq (6) shows that the foreign firm will produce the monopoly output for the foreign market. We then substitute the monopoly output $y^{f}=$ $(a-c) / 2 b$ into eq (4). Analysis of the resulting equation shows that the foreign firm is behaving as a monopolist because the foreign firm's government uses a prohibitive tariff. This tariff must be large enough that even if the domestic government is subsidizing exports the domestic firm will still be unable to export because of the tariff faced by this firm. Consequently $s^{d}+(a-c) / 2 \leq t^{f}$.

Using backward induction we find the Nash equilibrium

$$
\begin{aligned}
& \left(s^{d}, t^{d}\right)=\left(s^{d},(4 \theta-9)(a-c) /(2(8 \theta-15))\right), \\
& \left(s^{f}, t^{f}\right)=\left((3-4 \theta)(a-c) /(2(8 \theta-15)), t^{f} \geq s^{d}+(a-c) / 2\right) \\
& \left(x^{d}, x^{f}\right)=((4 \theta-7)(a-c) /(b(8 \theta-15))), \\
& \left(y^{d}, y^{f}\right)=((a-c) /((15-8 \theta) b), 0) .
\end{aligned}
$$

Analyzing these output levels we find that $x^{d}$ and $\mathrm{y}^{d}$ are nonnegative only for $0 \leq \theta<7 / 4$, while $\mathrm{y}^{f}>0$ for all $\theta$. This outcome is summarized in

Proposition 2 The strategy defined in eqs (14) - (17) is a corner, case 3, Nash equilibrium for all $\theta \in[0,7 / 4)$.

The Nash equilibrium strategies lead to payoffs that are a positive constant times some polynomial in $\theta$. By analyzing these polynomials the restrictions on $\theta$ that lead to a case 3 equilibrium can be exploited.

\footnotetext{
${ }^{5}$ Analysis of case 2 is available from the author upon request.
} 
The domestic firm will lose domestic market share as $\theta$ rises. Since the domestic firm has already been eliminated from the foreign market, because of the prohibitive tariff, it seems reasonable that the domestic firm would approach their government for trade protection. However, the domestic government finds that as $\theta$ rises its payoff will rise. The rise in social benefit comes from an increase in tariff revenue and a rise in consumer surplus. This latter effect occurs because the foreign subsidy will rise as $\theta$ rises. The increase in the domestic government's payoff from these two sources is greater than its loss from reduced domestic firm profit.

For the foreign government case 3 strategies will make $g^{f^{*}}$ rise for $0 \leq \theta<1.5716$ and decline for $1.5716<$ $\theta<7 / 4$. Consequently if case 3 strategies are used $\theta=1.5716$ seems like an efficient choice of $\theta$. However, analysis of eq (8) shows that $g^{f}$ is increasing in $\theta$ only if $0 \leq \theta<5 / 8$. For $5 / 8 \leq \theta<7 / 4 g^{f}$ will decline. In fact if $\theta>$ $1.6 g^{f}$ will be negative. To summarize, if a government is trying to maximize the social benefit function defined in eq (8) then some $\theta<1$ should be chosen, once again reversing the analysis of Trandel and Skeath (1996). ${ }^{6}$

The trade patterns that emerge with case 3 are reasonable and should exist in trade data. In case 3 the domestic firm and the foreign firm are using case 1, interior, strategies in the domestic economy. However, in the foreign economy the foreign government is using a prohibitive tariff to eliminate the domestic firm from the foreign market. Thus, the foreign firm can behave as a monopolist in its country. If the weight is in the interval $[0,3 / 2)$ and this equilibrium is chosen then the government is apparently not choosing a subgame perfect equilibrium, or perhaps domestic consumers are consciously choosing to purchase only domestic goods (which we do not model). The interior solution in the domestic economy is a consequence of a constant marginal cost, $\mathrm{c}$, which causes the foreign and domestic market to separate.

\subsection{Case 4: No Trade}

Case 4 is a combination of cases 2 and 3. In case 4 a prohibitive tariff used by both governments will lead to each firm acting as a monopolist in their respective domestic market. To derive the Nash equilibrium in this case we must analyze eqs (3) through (6). In these equations set $x^{f}=y^{d}=0$. Equations (4) and (5) must be less than or equal to zero. From eqs (3) and (6) we find that firms choose the monopoly output level. Given this output level eqs (4) and (5) define the optimal tariffs. Thus,

$$
\begin{aligned}
& \left(s^{d}, t^{d}\right)=\left(s^{d},(a-c) / 2+s^{f}\right), \\
& \left(s^{f}, f^{f}\right)=\left(s^{f},(a-c) / 2+s^{d}\right), \\
& \left.\left(x^{d}, x^{f}\right)=((a-c)) /(2 b), 0\right), \\
& \left(y^{f}, y^{d}\right)=(0,(a-c) /(2 b)),
\end{aligned}
$$

represents the case 4 Nash equilibriums strategies. This case is summarized in

Proposition 3: The strategy defined in eqs (18) - (21) is a case 4 Nash equilibrium for all $\theta$.

There are no comparative static results in $\theta$ since neither the policy or output variables change with $\theta$. The only comparative static result is that $g^{f *}$ is increasing in $\theta$. However, this result lacks meaning because for all $\theta$ output will not change neither will policy. For some values of $\theta$ Proposition 3 will be subgame perfect, see Figure 2 below.

\subsection{Case 5: Domestic Firm Ceases Production}

While case 5 is indeed an odd case it is still mathematically feasible, and perhaps case 5 trade policy does exist. In case 5 the domestic firm is forced out of the domestic and foreign market. After setting $x^{d}=x^{f}=0$ eqs (4) and (6) state that the foreign firm will produce as a monopolist in the foreign and domestic economy. The foreign

\footnotetext{
${ }^{6}$ The cause of the reversal of Trandel and Skeath's argument is the same as in the last subsection.
} 
firm produces as a monopolist in its domestic economy because the foreign government is using a prohibitive tariff. This prohibitive tariff is found by substituting the monopoly output level of $y^{f}$ into eq (4). From eq (5) we find that the foreign firm's export choice as a function of the export subsidy and the import tariff. With this information we can derive the optimal subsidy and tariff, which in turn defines the optimal choice of $y^{d}$. The Nash equilibrium strategy

$$
\begin{aligned}
& \left(s^{d}, t^{d}\right)=\left(s^{d},-(a-c) /(2 \theta-5)\right), \\
& \left(s^{f}, f^{f}\right)=\left(2(1-\theta)(a-c) /(2 \theta-5),(a-c) / 2+s^{d}\right), \\
& \left(x^{d}, x^{f}\right)=(0,0), \\
& \left(y^{d}, y^{f}\right)=((a-c) /(5-2 \theta),(a-c) /(2 b)),
\end{aligned}
$$

is restricted to $\theta \in[2,5 / 2)$. This restriction is necessary to satisfy the inequality found in eq (3). We summarize these results in

Proposition 4: The strategy of eqs (22) - (25) define a case 5 Nash equilibrium for all $\theta \in[2,5 / 2)$.

As in the other cases the payoff to each player from the case 5 Nash equilibrium strategies can be written as a positive function of $\theta$ times a polynomial in $\theta$, except for the domestic firm who is receiving a payoff of zero. Consequently, we can analyze each payoff and strategy choice to see how it is affected by changes in $\theta$.

This choice of $y^{d}$ is very sensitive in case 5 . Note that the foreign firm's exports are increasing in $\theta$. At $\theta=$ 2 the foreign firm's output choice is twice the monopoly output. As $\theta$ increases the foreign firm would be producing more than twice the monopoly output. In fact, case 5 would likely be eliminated as an equilibrium if a capacity constraint on this firm were added.

Even with the domestic firm producing no output the social benefit function of the domestic government would increase as $\theta$ increased. If $\theta \in[2,5 / 2)$ the domestic government would have to choose between case 4 and case 5 strategies. Faced with this choice, case 5 would be preferred. Case 5 provides domestic consumers with over twice the output of case 4 , and this increase in output is completely subsidized by the foreign government. In addition, the domestic government is extracting tariff payments from the foreign firm.

For the foreign government $g^{f^{*}}$ is declining for all $\theta \in[2,5 / 2)$. Consequently, $g^{f^{*}}$ is maximized at $\theta=2$. Given this value of $\theta$ the case 4 and case 5 values of $g^{f^{*}}$ are equal; thus, the foreign government should be indifferent between these cases. However, as $\theta$ rises case 4 is definitely preferred to case 5. Actual social benefit as defined in eq (8) will be negative for $\theta \in[2,5 / 2)$.

\section{Equilibrium Analysis}

The five cases defined in Table 1 exhaust the potential Nash equilibrium outcomes of this model. The intervals over which these cases are Nash equilibria depend on $\theta$ as illustrated in Figure 1. The occurrence of multiple Nash equlibria, caused by the inclusion of the corner solutions, begs the question: is one equilibrium preferred to another? We define preferred to mean that both governments receive a greater payoff using one equilibrium strategy than they could using some other equilibrium strategy. In Figure 2 we have identified the intervals where a preferred, subgame perfect, equilibrium exists. In this section we analyze each interval from Figure 1 to justify why a preferred equilibrium does or does not exist. 


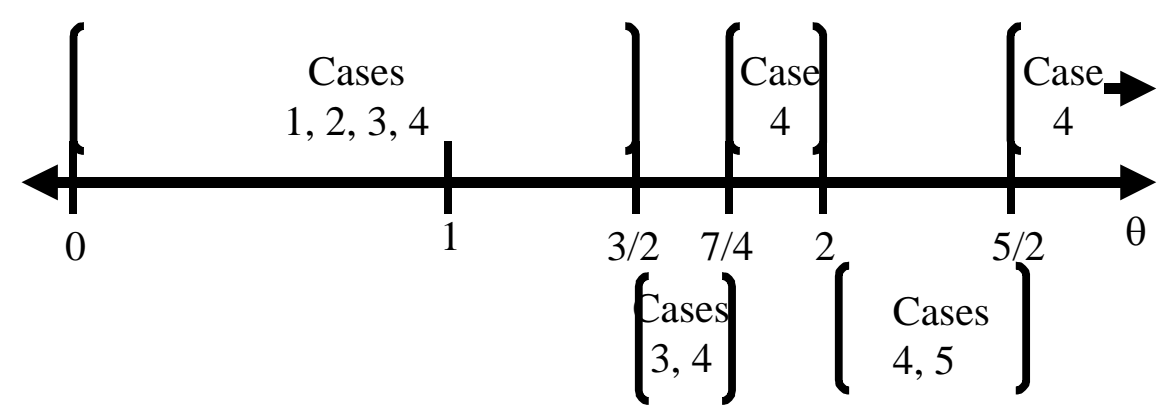

Figure 1

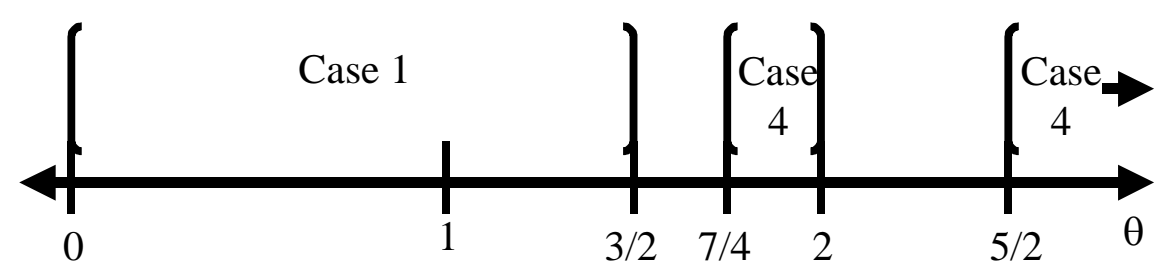

Figure 2

The policy stage, stage one, of this model is all we need when searching for a preferred equilibrium, because the best a stage two player can do is choose an optimal output level in response to stage one policy. Thus, the policies of stage one control the outcome of this game. In this analysis we use $g^{f^{*}}$, eq (9) to define the foreign government's payoff in each region defined in Figure 1. The choice of $g^{f^{* *}}$ seems logical since it is this function that the foreign government is using to make its optimal policy choice.

For $0 \leq \theta<3 / 2$ the domestic government strictly prefers case 1 outcomes. In this interval the foreign government also prefers case 1 outcomes, although the distances between case 1 , case 2 , case 3 , and case 4 payoffs are narrower for the foreign government. Thus, for both players, case 1 strategies provide higher payoffs than any of the other cases. As can be seen in eqs (10) - (13) the equilibrium case 1 strategies will vary as $\theta$ varies. The equilibrium $t^{d}, t^{f}$, and $s^{d}$ will remain positive for all $\theta \in[0,3 / 2)$; however, the value of $s^{f}$ is not always positive over this same interval. For $\theta \in[0,3 / 4)$ the optimal value of $s^{f}$ will be negative. Thus, for weights in this interval the foreign government's optimal export subsidy is actually an export tax. However, for $\theta \in(3 / 4,3 / 2)$ the foreign government's optimal export subsidy will be positive. As was noted in section 3 that actual social benefit, defined in eq (8), suggests that a $\theta \in[0,3 / 4)$ be used to maximize social benefit. Consequently, if the foreign government's objective is to maximize social benefit an export tax should be used.

Analysis of $\theta \in(3 / 2,7 / 4)$ is not as straightforward; there is no strictly preferred pure strategy. In this interval, the domestic government prefers case 3 to case 4 strategies. The case 3 strategy implies $x^{f}=0$, while all other output levels are positive. Thus, the domestic government's strategy choice in this interval allows its domestic producer to compete as a Cournot oligopolist domestically, but the domestic government cannot help the domestic firm gain entrance in the export market. Furthermore, given the separability of the import and export market, the domestic government has no incentive to reduce $y^{d}$, through tariff policy, for any $\theta .^{7}$

\footnotetext{
${ }^{7}$ The point we are trying to make is that the domestic government does not wish to punish the foreign government for excluding the domestic firm from the export market. The best the domestic government can do is use the optimal tariff for a given $\theta$.
} 
For $\theta \in(3 / 2,7 / 4)$ the foreign government prefers to implement its case 4 strategy to the strategy of case 3 . This occurs because using case 3 strategies means that the foreign government will pay a subsidy to its exporter, subsidizing consumption in the foreign firm's export market. However, the foreign government is forcing foreign consumers, the foreign government's domestic constituency, to pay a higher price for output, because $y^{f}$ is produced at the monopoly level. When case 4 strategies are used, the foreign government no longer provides an export subsidy, which increased the foreign government's social benefit relative, even with the foreign firm's reduction in profit, to case 3 .

Because the domestic government prefers case 3 outcomes and the foreign government prefers case 4 outcomes, no strategy is preferred in this interval. However, there is one special case. Because the foreign government is free to choose $s^{f}$ when playing the case 4 strategy, if the foreign government happened to choose $s^{f}$ at the case 1 or case 3 level, while the domestic government chose the case 3 strategy, then a case 3 outcome would prevail. Admittedly, this is a special case and perhaps a more satisfying solution to the non-unique outcome on this interval would be an equilibrium in mixed strategies, which we do not provide.

Case 3 trade patterns have existed. This pattern is reminiscent of Kodak and Fuji films. These producers compete as oligopolists in the U.S. market; however, Fuji behaves more like a monopolist in the Japanese market. It is also reminiscent of competition between Boeing and Airbus. The U.S. market is largely controlled by Boeing, while the rest of the world market is more evenly split.

For $\theta \in(7 / 4,2)$ and $\theta>5 / 2$ both players prefer case 4 strategies. Throughout $\theta \in(3 / 2,7 / 4)$ the domestic government's tariff, $t^{d}$, is increasing. As $\theta$ approaches $7 / 4, t^{d}$ approaches the prohibitive level and, as $7 / 4<\theta<2$ is entered, the domestic government will join the foreign government in case 4 strategies. The switching by the domestic government to case 4 strategies in a sense measures the domestic government's tolerance for the foreign government's industrial policy. Once $7 / 4<\theta<2$ is entered, the case 4 no trade equilibrium is the unique outcome. These trade patterns can be found historically; for example, trade between India and the United States in steel is non-existent. This commodity demonstrates the characteristics of a good that could have intra-industry trade patterns. However, India's internal policy does not allow this trade to occur.

Finally, for $2 \leq \theta<5 / 2$ there does not exist a preferred equilibrium. The domestic government prefers the case 5 outcome, but the foreign government prefers the case 4 outcome. Case 5 is truly an odd outcome and with some introspection could likely be eliminated. The foreign firm's ability to produce case 5 output will likely be eliminated if a capacity constraint on production were imposed. Furthermore, the price faced by domestic consumers in case 5 would approach zero given the flood of imports. For these two reasons, case 5 strategies are not likely even if the domestic government prefers this outcome.

\section{Conclusion}

It has been shown that by including a weight, $\theta$, in the foreign government's social benefit function, and by performing a complete analysis of the two stage intra-industry trade game, which must include the nonnegativity constraints on each firm's output variables, introduces additional, non-interior, Nash equilibria. This simple extension helps to explain why industries that satisfy the necessary conditions for intra-industry trade patterns may not actually display such trade patterns. Cases 2 through 5 demonstrate non-interior trade patterns. To make the analysis of cases 2 through 5 even more interesting we suggest that the firms in this model would actively lobby their government in order to influence the weight chosen by the foreign government. However, as was shown, and as Collie (1997) has shown, if a government's desire is to maximize social benefit then a weight less than one would be more appropriate. At the interior solution the optimal weight used by the foreign government leads to a tariff on imports, but they will also tax exports.

Should the foreign government choose a weight larger than one the results suggest a policy strategy for the domestic government. If the domestic firm is pressuring the domestic government, because the foreign government is actively subsidizing the foreign firm, the domestic government does have a politically palatable solution. They 
can raise the tariff on imports, appeasing domestic firms, and lower their own export subsidy, appeasing the rest of the world.

To summarize it was found that for $\theta \in[0,3 / 2)$ there are four Nash equilibria. In this interval the payoff received from case 1 strategies, a strictly interior solution, exceeds the payoffs received in any of cases 2,3 , and 4 . Thus, in this interval, traditional intra-industry trade patterns are expected to occur. To explain a non-interior solution in this interval would be to claim that the policy makers are not choosing a subgame perfect equilibrium.

For $\theta \in(3 / 2,7 / 4)$ case 3 and 4 are both Nash equilibria. We found that, for the domestic government, the case 3 strategy strictly dominates the case 4 strategy for all $\theta$ in this interval. For the foreign government, the case 4 strategy strictly dominates the case 3 strategy for all $\theta$ in this interval. While no preferred solution appears in this interval, two things are clear: the interior solution is not an option and trade patterns will not resemble tradition intra-industry trade patterns.

For $\theta \in(7 / 4,2)$ and $\theta>5 / 2$ a unique subgame perfect equilibrium does exist. The domestic government and the foreign government both use their case 4 strategy and no trade occurs.

Finally, for $\theta \in[2,5 / 2)$ there does not exist a unique pure strategy equilibrium. In this interval the domestic government always prefers the case 5 strategy relative to the case 4 option, while the foreign government will prefer the case 4 outcome. Consequently, no unique equilibrium in pure strategies exists; however, once again an interior solution is not an option.

\section{References}

1. Brander, James A. and Spencer, Barbara J., "Export Subsidies and International Market Share Rivalry" Journal of International Economics, 1985, 18, 83-100.

2. Collie, D., "Delegation and Strategic Trade Policy" International Economic Journal, 1997, 11, 35-46.

3. Dixit, A., "International Trade Policy for Oligopolistic Industries" Supplement to the Economic Journal 1984, 94, 1-16.

4. Eaton, J. and Grossman, G., "Optimal Trade and Industrial Policy Under Oligopoly" Quarterly Journal of Economics 1986, 101, 383-406.

5. Trandel, G. and Skeath, S., "Playing Favorites: Welfare Effects when Strategic Trade Policy is set to Favor Producers" Southern Economics Journal 1996, 63, 163-171. 